\title{
Improvement of corner separation prediction using an explicit non-linear RANS closure
}

\section{Original article}

Article history:

Submission date: 7 November 2020

Acceptance date: 3 March 2021

Publication date: 9 April 2021

This is the updated version of a paper originally presented at the Global Power and Propulsion Virtual Technical Conference, GPPS Chania20, Sept. 7-9, 2020.

\section{Check for updates}

*Correspondence:

Ws: ws344@acam.ac.uk

\section{Peer review:}

Single blind

\section{Copyright:}

(c) 2021 Sun and $\mathrm{Xu}$ () This is an open access article distributed under the Creative Commons Attribution Non Commercial No Derivatives License (CC BY-NC-ND 4.0). Unrestricted use, distribution, and reproduction of the original work are permitted for noncommercial purposes only, provided it is properly cited and its authors credited. No derivative of this work may be distributed.

\section{Keywords:}

axial compressors; turbulence modelling; corner separation; CFD

\section{Citation:}

Sun W., Xu L. (2021). Improvement of corner separation prediction using an explicit non-linear RANS closure. Journal of the Global Power and Propulsion Society. 5: $50-65$.

https://doi.org/10.33737/jgpps/133913
Wei Sun ${ }^{1, *}$, Liping $X u^{1}$

${ }^{1}$ Whittle Laboratory, University of Cambridge, Cambridge, United Kingdom

\begin{abstract}
In this paper, an investigation into the effect of explicit non-linear turbulence modelling on anisotropic turbulence flows is presented. Such anisotropic turbulence flows are typified in the corner separations in turbomachinery. The commonly used Reynolds-Averaged Navier-Stokes (RANS) turbulence closures, in which the Reynolds stress tensor is modelled by the Boussinesq (linear) constitutive relation with the mean strain-rate tensor, often struggle to predict the corner separation with reasonable accuracy. The physical reason for the modelling deficiency is partially attributable to the Boussinesq hypothesis which does not count for the turbulence anisotropy, whilst in a corner separation, the flow is subject to three-dimensional (3D) shear and the effects due to turbulence anisotropy shall not be ignored. Considering this, an explicit non-linear Reynolds stress-strain constitutive relation developed by Menter et al. is adopted as a modification of the Reynolds stress anisotropy. Coupled with the Menter's hybrid $k-\omega / k-\varepsilon$ turbulence model, this nonlinear constitutive relation gives significantly improved predictions of the corner separations in a compressor cascade, at both the design and off-design flow conditions. The study of the mean vorticity field reveals the physical reasons for the prediction improvement, thus highlighting the rationality of the explicit anisotropic correction for the corner separation prediction.
\end{abstract}

\section{Introduction}

Corner separation is one kind of the 3D separated flows that is commonly observed at the junction of the endwall and blade suction surface within axial compressors. At off-design flow conditions, this separation can appear to be large and localized, which can contribute significantly to the passage blockage. This places a limit on the loading and static pressure rise achievable by the compressor (Gbadebo et al., 2005). Furthermore, once flow separates, the mixing within the separation region, and the mixing of the separated flow with the main passage flow may lead to a considerable stagnation pressure loss and thus reduction in the compressor efficiency (Dong et al., 1986). Therefore, it is necessary for Computational Fluid Dynamics (CFD) to predict corner separation and its consequences with good confidence, in order for it to be used as a reliable design and analysis tool.

Despite the significant advances in the scale-resolving simulation techniques in industrial CFD, RANS is still widely used in the industrial flow simulations, and will remain in high demand at least until the mid-21st century (Spalart, 2015). This is largely because of its costeffectiveness, numerical robustness, and relatively easy of use. However, several eddy-viscosity based turbulence closure models that are 
commonly used in industry, such as the Spalart-Allmaras (SA) model (Spalart and Allmaras, 1992) and the Menter's hybrid $k-\omega / k-\varepsilon$ model (Menter, 1994; Menter et al., 2003), were found to over-predict the extent of corner separation (Liu et al., 2016; Lu et al., 2016). One of the sources of modelling uncertainties occurs in the Boussinesq constitutive relation, which was introduced for the Reynolds-stress closure in the mean transport equations. This constitutive relation implies the instantaneous values of the Reynolds stress tensor be linearly related to the local mean strain-rate tensor via the eddy viscosity $v_{t}$ (Boussinesq, 1903). Herein $v_{t}$ is a scalar variable and this constitutive relation between the fluctuating and mean fields is hypothesized to be the same in all directions (Mishra and Iaccarino, 2017) . For simple shear flows where the principle shear stress plays a dominant role in the mean momentum transport equations, the Boussinesq constitutive relation in many times gives fairly close approximations for the mean flow field, even though the predictions for the Reynolds normal stresses are not satisfactory. That is, the Reynolds normal stresses in all three directions are set to be equal, i.e. $\overline{\left(u^{\prime}\right)^{2}}=\overline{\left(v^{\prime}\right)^{2}}=\overline{\left(w^{\prime}\right)^{2}}$. However, for 3D complex shear flows where turbulence could be highly anisotropic, the Boussinesq hypothesis will force an isotropic distribution of turbulence kinetic energy (TKE) from different components of fluctuating velocities, which is non-physical in nature.

To reduce the modelling uncertainties for corner flows, a number of studies have been available focusing on mathematically formulating the nonlinear stress-strain relation for more turbulence anisotropic effects to be realistically modelled, e.g., Pope (1975), Hanjalić and Launder (1976), Gatski and Speziale (1993), Spalart (2000), and Hellsten and Wallin (2009). As explained by Gatski and Speziale (1993), the secondary flow of the second kind, as observed around corners, acts as one of the main physical mechanisms to determine the location of the corner separation onset. In other words, it is observed that the secondary flow driven by the anisotropy in the Reynolds normal stresses extracts momentum from the main passage flow into the corner. This leads to the corner flow being more resistant to the adverse pressure gradient, and thus delays the separation onset. The secondary flow of the second kind can only be captured via the incorporation of higher-order terms in the stressstrain relation. All turbulence closures that are based on the linear stress-strain relation are intrinsically incapable to predict this flow phenomenon.

In the current paper, the primary goal is to investigate the predictive capabilities of a recently developed nonlinear stress-strain relation (Menter et al., 2018) for the secondary flows in corners. This is an explicit constitutive relation which is capable of reproducing turbulence anisotropy without a large penalty on model simplicity, computational cost, and numerical robustness. Coupled with the Menter's hybrid $k-\omega / k-\varepsilon$ model, it is validated for the corner separation flows within a compressor stator cascade under various inflow conditions. The mean vortical flow field around the corner is then investigated to demonstrate its effectiveness on suppressing the premature separation from the corner.

\section{Model formulation}

\section{The explicit quadratic constitutive relation}

By adding various forms of the scalar product of second-order tensors (i.e., mean strain-rate tensor and mean vorticity tensor), the Menter et al.'s nonlinear stress-strain constitutive relation is regarded as an explicit extension of the Boussinesq constitutive relation, which is shown as follows (Menter et al., 2018):

$$
\begin{gathered}
\tau_{i j}=\tau_{i j}^{E V}-C_{\text {CORNER }} \frac{1.2 v_{t}}{\max \left(0.3 \omega, \sqrt{0.5\left(S^{2}+\Omega^{2}\right)}\right)}\left(S_{i k} \Omega_{k j}-\Omega_{i k} S_{k j}\right) \\
\tau_{i j}^{E V}=-\frac{2}{3} k \delta_{i j}+2 v_{t} S_{i j} \\
S_{i j}=\frac{1}{2}\left(\frac{\partial u_{i}}{\partial x_{j}}+\frac{\partial u_{j}}{\partial x_{i}}\right) \quad S=\sqrt{2 S_{i j} S_{i j}} \quad \Omega_{i j}=\frac{1}{2}\left(\frac{\partial u_{i}}{\partial x_{j}}-\frac{\partial u_{j}}{\partial x_{i}}\right) \quad \Omega=\sqrt{2 \Omega_{i j} \Omega_{i j}}
\end{gathered}
$$

where $\tau_{i j}^{E V}, S$, and $\Omega$ denote the Reynolds stress tensor computed using the Boussinesq hypothesis, the strain-rate magnitude, and the vorticity magnitude, respectively. $C_{\text {CORNER }}$ is an adjustable constant coefficient that controls the strength of turbulence anisotropy, with a recommended range between 0 and 1.5 and the default value as 1.0. As equation (1) shows, the proposed constitutive relation was designed in combination with the $k-\omega$ type models to close the RANS governing equations. And here the Menter's hybrid $k-\omega / k-\varepsilon$ model is adopted, which avoids the model sensitivities to freestream turbulent variables (Wilcox, 1988). 
The Menter's hybrid $k-\omega / k-\varepsilon$ model from 2003 (BSL-2003)

The Menter's hybrid $k-\omega / k-\varepsilon$ model along with the eddy viscosity definition read as follows (Menter et al., 2003):

$$
\begin{gathered}
\frac{\partial k}{\partial t}+\frac{\partial\left(u_{j} k\right)}{\partial x_{j}}=\widetilde{P}_{k}-\beta^{*} k \omega+\frac{\partial}{\partial x_{j}}\left[\left(v+\sigma_{k} v_{t}\right) \frac{\partial k}{\partial x_{j}}\right] \\
\frac{\partial \omega}{\partial t}+\frac{\partial\left(u_{j} \omega\right)}{\partial x_{j}}=\frac{\gamma}{\nu_{t}} \widetilde{P}_{k}-\beta \omega^{2}+\frac{\partial}{\partial x_{j}}\left[\left(v+\sigma_{\omega} v_{t}\right) \frac{\partial \omega}{\partial x_{j}}\right]+2\left(1-F_{1}\right) \frac{\sigma_{\omega 2}}{\omega} \frac{\partial k}{\partial x_{j}} \frac{\partial \omega}{\partial x_{j}}
\end{gathered}
$$

where the production of TKE $\widetilde{P}_{k}$ is defined as:

$$
\widetilde{P}_{k}=\min \left(\tau_{i j} \frac{\partial u_{i}}{\partial x_{j}}, 10 \beta^{*} k \omega\right)
$$

The turbulent eddy viscosity is computed as:

$$
v_{t}=\frac{k}{\omega}
$$

\section{Computational details}

\section{Flow solver}

In the current research, all validation cases are conducted using the ANSYS FLUENT solver, in which the above explicit quadratic constitutive relation is activated and modified via the user-defined macros. The numerical scheme adopted is the pressure-based pressure-velocity segregated algorithm, with the second-order upwind scheme used for the discretization of convection terms in all transport equations. For pressure interpolation the second-order scheme is adopted, and the gradients are approximated with the use of the node-based Green-Gauss method.

\section{The LMFA-NACA65 cascade}

A linear compressor cascade which was experimentally investigated by Ma et al. (2011) and Zambonini et al. (2016) at Laboratoire de Mécanique des Fluides et d'Acoustique (LMFA) is used here for the numerical investigation of corner separation. The LMFA-NACA65 compressor cascade consists of 13 NACA65-009 blades mounted at the end of an open circuit subsonic wind tunnel. In the experiment, two strips of sandpaper with $3.0 \mathrm{~mm}$ width by $0.3 \mathrm{~mm}$ thickness were stuck at an arc length of $6 \mathrm{~mm}$ from the leading edge of both the blade suction and pressure surfaces. The aim is to trigger the laminar-to-turbulent transition process at the early stage of the blade surface boundary layer development, whereby removing the impact of boundary layer transition on the downstream corner separation. This contributes to reducing the difficulties of RANS simulations, as no transitional model is needed in addition to the fully turbulent RANS models. The main geometrical parameters are presented in Table 1 (Zambonini et al., 2016).

\section{Mesh}

The computational domain for the LMFA-NACA65 cascade is shown in Figure 1. The inlet plane is located at $2.16 c_{x}$ in the axial direction upstream of the leading edge, the same as the location of hot-wire measurements for the incoming endwall boundary layer (Ma et al., 2011; Zambonini et al., 2016). The outlet plane is placed at $1.36 c_{x}$ in the axial direction downstream of the trailing edge, the same as the location of the outlet of cascade test rig.

As the pitchwise periodicity of the time-mean flow was ensured throughout the measurement process (Ma et al., 2011), one single blade passage is simulated, with the pitchwise boundaries set as translational periodicity. 
Table 1. Geometrical parameters.

\begin{tabular}{|l|c|}
\hline Parameter & Value \\
\hline Blade chord $c(\mathrm{~mm})$ & 150.0 \\
\hline Blade axial chord $c_{x}(\mathrm{~mm})$ & 110.0 \\
\hline Blade aspect ratio $h / c$ & 2.47 \\
\hline Pitch to chord ratio $s / c$ & 0.893 \\
\hline Blade camber angle $\varphi\left(^{\circ}\right)$ & 23.22 \\
\hline Blade stagger angle $\gamma\left({ }^{\circ}\right)$ & 42.7 \\
\hline Blade inlet angle $\beta_{1}\left({ }^{\circ}\right)$ & 54.31 \\
\hline
\end{tabular}

Furthermore, as the surface oil flow measurements indicate the flow symmetry with respect to the mid-span (Ma et al., 2011), one half of the blade span is simulated, with the mid-span boundary set as symmetry.

As for the mesh topology, an $\mathrm{O} 4 \mathrm{H}$ topology is used, and hexahedral meshes are generated using NUMECA Autogrid $^{\mathrm{v}}$. 376 points are wrapped around the blade and in the near-wall region above the blade surface $(\mathrm{O}$ block), 41 points are distributed in the wall-normal direction, with the average $y^{+}$less than 1.0 and the near-wall grid expansion ratio about 1.15. In the spanwise direction, 97 points are distributed, with the maximum $y^{+}$ around 1.0 and the near-wall grid expansion ratio less than 1.2. Overall, the mesh consists of about 3.04 million hexahedral cells.

\section{Boundary conditions}

As for the mean-flow boundary conditions, the inlet mean velocity profile, flow angle, density, static temperature, and the outlet mean static pressure are prescribed to match the experimental measurements. At inlet, the velocity profile is specified based on a precursor RANS simulation on a zero-pressure-gradient flat plate turbulent boundary layer, with the results of which matching the single hotwire measurements of the cascade inlet endwall boundary layer. Figure 2 compares the computed inflow velocity profile with the experimental measurements (Zambonini et al., 2016). It can be shown that the extracted velocity profile almost reproduces the measurements. The inlet freestream flow parameters are listed in Table 2 and the inlet boundary layer integral parameters are listed in Table 3.

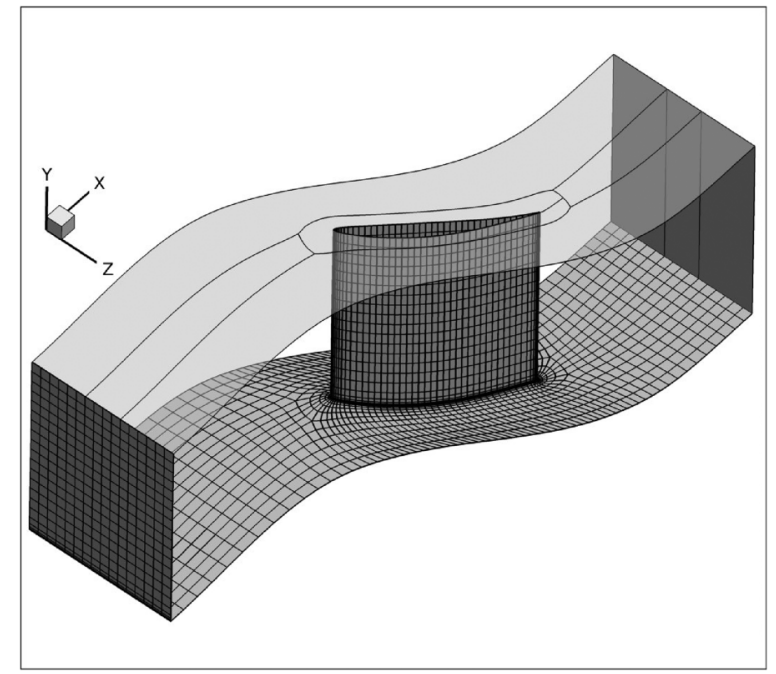

Figure 1. Computational domain (1 every 4 grid points shown for visual clarity). 


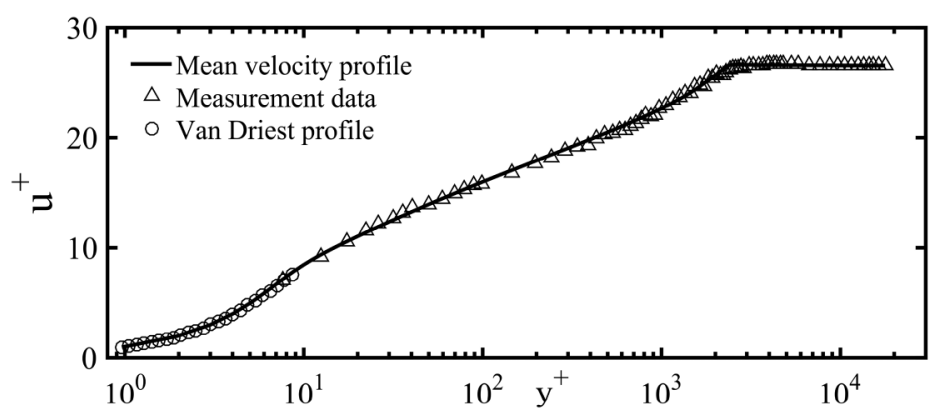

Figure 2. Inflow velocity profile in logarithmic plot.

As for the inlet turbulence specification, no detailed hotwire measurements of the fluctuating velocities inside the endwall boundary layer are available. Some uncertainties thus inevitably exist on the treatment of the inlet turbulence boundary conditions. Here the extracted boundary layer velocity profile, as well as the corresponding profiles of turbulent variables (TKE $k$ and specific dissipation rate $\omega$ ), were imposed on the cascade inlet plane.

\section{Results and discussion}

\section{Model validation}

In this section, two flow cases for the LMFA-NACA65 compressor cascade are computed and discussed. The purpose is to demonstrate that compared with the BSL-2003 model with the Boussinesq constitutive relation (BSL-2003-L), BSL-2003 with the above-mentioned nonlinear stress-strain constitutive relation (BSL-2003-NL) yields improved predictions of the size of corner separation at various flow conditions.

\section{Case $1\left(i=0^{\circ}\right)$}

Figure 3 compares the surface limiting streamlines distribution by the BSL-2003-L and BSL-2003-NL models at the design flow condition. As shown on the endwall surface, the boundary layer predicted by the BSL-2003-NL model exhibits stronger resistance to the adverse pressure gradient when migrating to the blade suction surface, thus

Table 2. Inlet freestream flow parameters.

\begin{tabular}{|l|l|}
\hline Parameter & Value \\
\hline Chord-based Reynolds number, $R e_{c}$ & $3.82 \times 10^{5}$ \\
\hline Inlet freestream Mach number, $M$ & 0.12 \\
\hline Inlet freestream turbulence intensity, Tu & $0.8 \%$ \\
\hline
\end{tabular}

Table 3. Inlet endwall boundary layer integral parameters.

\begin{tabular}{|l|l|}
\hline Parameter & Value \\
\hline Non-dimensional inlet endwall boundary layer thickness, $\delta_{1} / h$ & $8.11 \times 10^{-2}$ \\
\hline Inlet endwall boundary layer displacement thickness, $\operatorname{Re}_{\delta^{*}}$ & 9,439 \\
\hline Inlet endwall boundary layer momentum thickness, $R e_{\theta}$ & 7,130 \\
\hline Inlet endwall boundary layer shape factor, $H$ & 1.32 \\
\hline
\end{tabular}



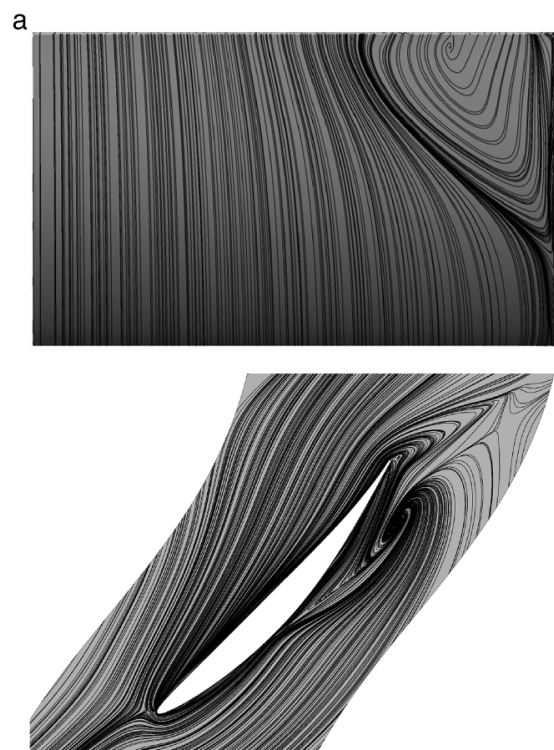
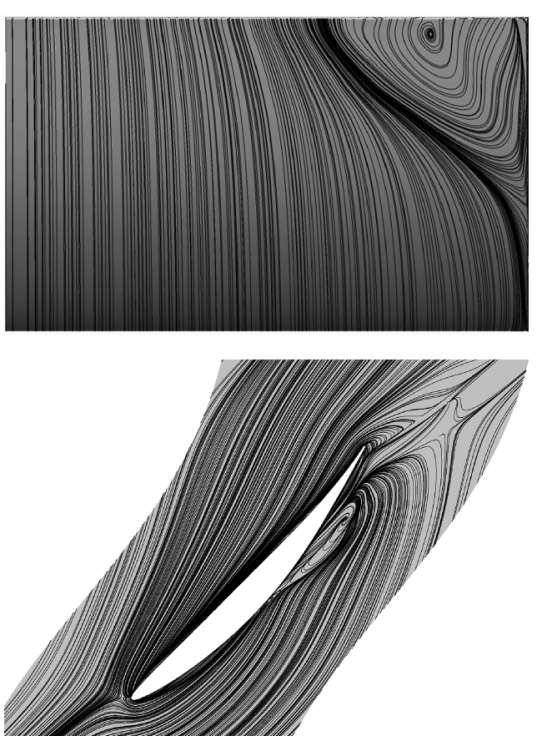

Figure 3. Surface flow visualization $\left(i=0^{\circ}\right)$. (a) BSL-2003-L, (b) BSL-2003-NL.

leading to the smaller size of corner separation and the delayed onset of separation. On the suction surface, the corner separation size predicted by BSL-2003-NL is also shown to be smaller in the chordwise direction than that by the BSL model with the linear Reynolds stress closure. The validation results confirm that the addition of the anisotropic effect of turbulence in the corner region acts to suppress the over-prediction of corner separation.

To see how the overpredicted blockage affects the blade loading, Figure 4 presents the distributions of static pressure coefficient $C_{p s}$ on the blade surface. Above the endwall separation region (above 20\%h), as shown in Figure $4 \mathrm{a}$ and $4 \mathrm{~b}$, no separation occurs on the blade surface, and the blade loading predicted by both models matches closely with the experimental measurements. This indicates that the spanwise extent of corner separation does not exceed $20 \%$ of the blade span. Furthermore, the original BSL-2003 model predicts the pressure loading a bit lower than measurements on the pressure surface, indicating a larger corner separation predicted in the pitchwise direction (see also in Figure 3). Due to the larger passage blockage predicted, more flow is pushed towards the pressure surface, leading to the pressure reduced on the pressure surface due to increased velocity.

In the endwall separation region, the original BSL-2003 model predicts premature corner separation, while the BSL-2003 model with the explicit nonlinear turbulence closure almost reflects the real flow field. As seen in
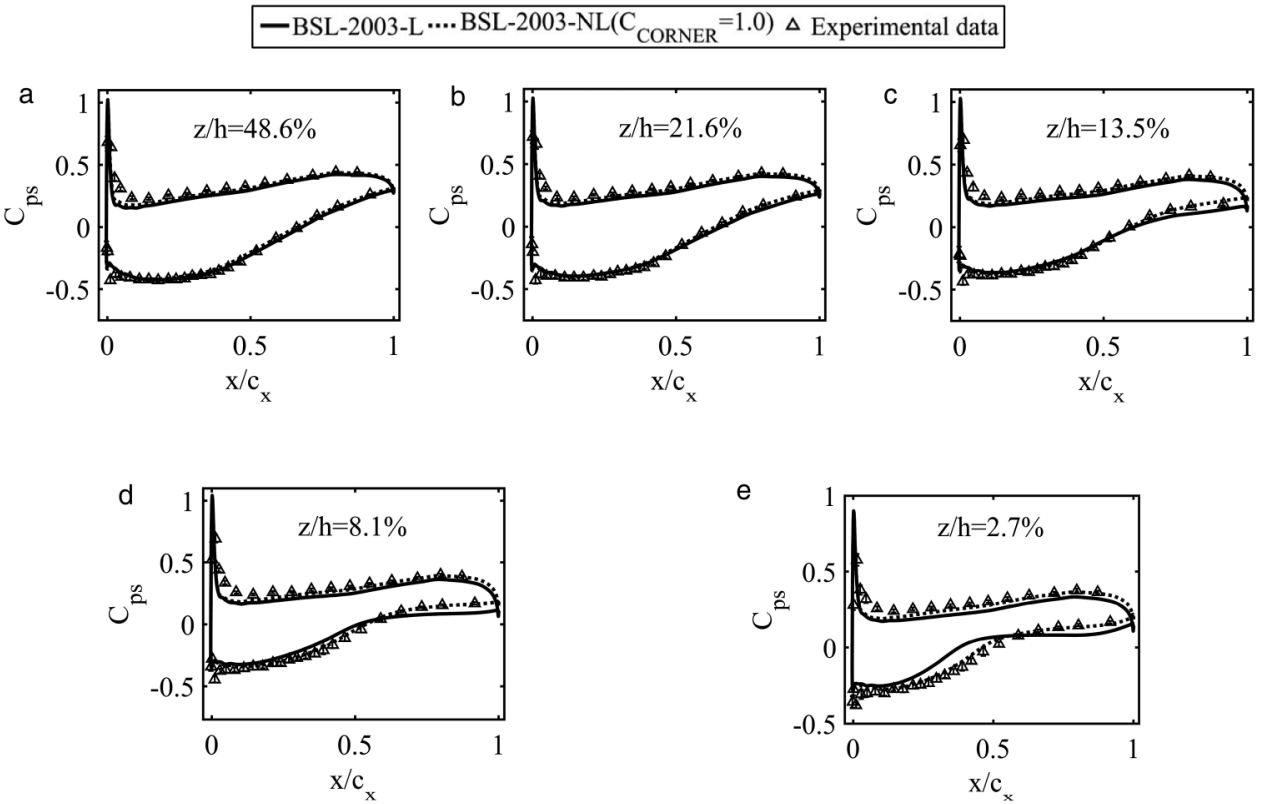

Figure 4. Blade spanwise $C_{p s}$ distributions $\left(i=0^{\circ}\right)$. 
Figure 4c and 4d, the BSL-2003-L model results in the early boundary layer separation on the suction surface. In contrast, a better pressure recovery is achieved by BSL-2003-NL in the rear part of the suction surface, which matches closely with the experimental measurements. However, in the region closest to the endwall (2.7\%h), the BSL-2003-L model results in the overprediction of both the streamwise and pitchwise extent of corner separation, while the BSL-2003-NL model gives results that almost reproduce measurements. This indicates that the corner separation size can be predicted with high accuracy if the anisotropic properties of the flow in the corner region are reasonably modelled.

Overall, it is encouraging to see that the prediction results for corner separation are quite promising. This means that some of the corner separation physics is reasonably captured by addition of the quadratic strainvorticity term to the Boussinesq constitutive relation.

Next, the validation results of a more challenging flow case are shown to highlight the generality of this nonlinear stress-strain relation for the corner separation prediction.

\section{Case $2\left(i=2^{\circ}\right)$}

At the off-design flow condition, as with the design condition, the shrink of the size of corner separation is observed in both the chordwise and pitchwise directions (see in Figure 5). However, the spanwise extent of corner separation turns to be larger than that predicted by the original BSL model. This is due to the increased spanwise velocity close to the blade suction surface within the separation region, a resulting effect of the reconstruction of Reynolds stresses in the spanwise momentum transport equation.

Figure 6 shows the effect of the predicted corner separation on the blade loading distribution. Above the endwall separation (above 27\% h), the loading predicted by both models matches closely with measurements. However, moving down into the endwall separation region, as shown in Figure 6c, a "pressure plateau" from $0.6 c_{x}$ towards the trailing edge is predicted by BSL-2003-L, indicating an overly large corner separation in the streamwise direction $\left(0.06 c_{x}\right.$ larger than measurements). In contrast, a pressure recovery that closely matches the measurements is predicted by BSL-2003-NL at $13.5 \% \mathrm{~h}$. Furthermore, as seen from Figure 6d, the BSL-2003-NL model significantly improves the predictions of both the separation onset and blade loading. This indicates that a significantly improved prediction of the chordwise and pitchwise extent of corner separation is achieved by enhancement of turbulence anisotropy in the endwall flow region. This is achieved by a simple nonlinear expansion of the Boussinesq eddy-viscosity hypothesis.

However, in the region closest to the endwall (see in Figure 6e), the BSL-2003-NL model predicts the corner separation onset earlier than measurements. One of the physical reasons is hypothesized to be the underestimation of the anisotropic effects of turbulence in the corner separation. As explained in the section "model formulation", $C_{\text {CORNER }}$ controls the strength of turbulence anisotropy, with the default value of which being calibrated in the outer layer of a simple wall shear layer by requiring a fair level of the normal stress anisotropy

a
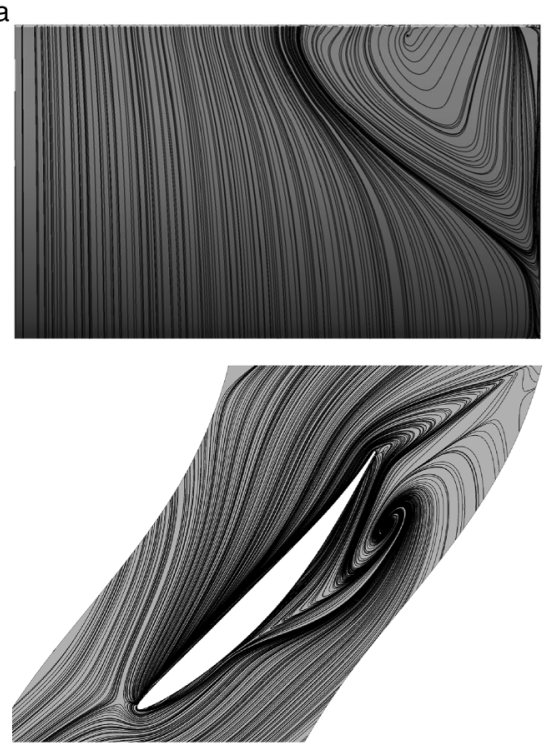
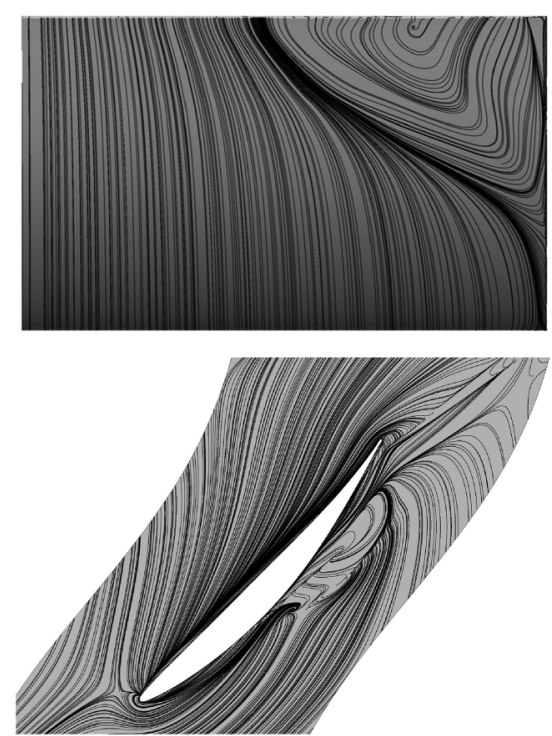

Figure 5. Surface flow visualization $\left(i=2^{\circ}\right)$. (a) BSL-2003-L. (b) BSL-2003-NL. 
-BSL-2003-L $\cdots$ B..BSL-2003-NL(C $\left.\mathrm{CORNER}_{\text {B }}=1.0\right) \Delta$ Experimental data

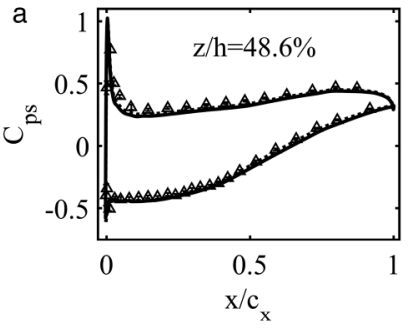

d

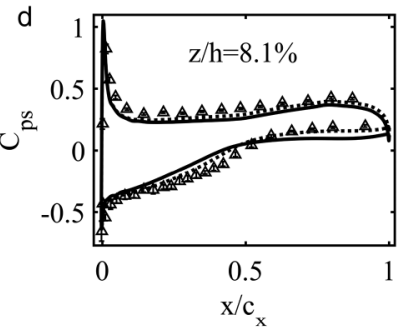

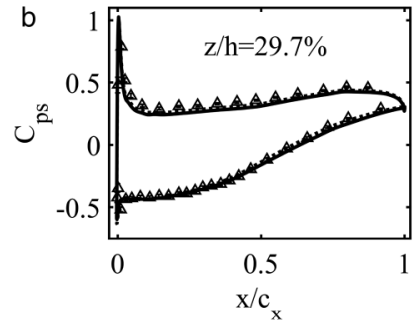
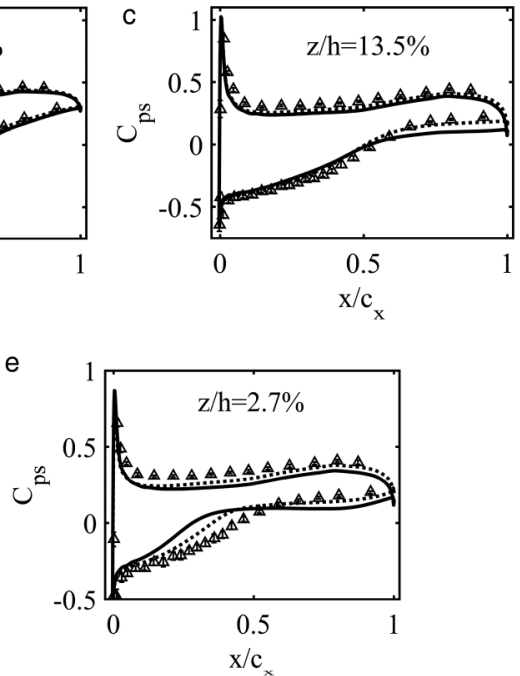

Figure 6. Blade spanwise $C_{p s}$ distributions $\left(i=2^{\circ}\right)$.

$\overline{\left(u^{\prime}\right)^{2}}>\overline{\left(w^{\prime}\right)^{2}}>\overline{\left(v^{\prime}\right)^{2}}$. Here it shall be pointed out that the chosen $C_{\mathrm{CORNER}}$ value is preliminary for the $3 \mathrm{D}$ complex separated flows. For further improvement of Menter et al.'s explicit anisotropic correction model, it would be beneficial if systematic optimization of the $C_{\text {CORNER }}$ was carried out based on the high-fidelity large eddy simulation (LES) database of the compressor cascade flows at various operating conditions.

In the next section, the flow field around the corner region will be analysed to reveal the effect of the anisotropic modification on the mean flow field.

\section{Flow field analysis}

Figure 7 compares the size of corner separation via the distribution of the eddy-to-molecular viscosity ratio $\left(v_{t} / v\right)$ around the trailing edge. The cut plane is placed just downstream of the blade trailing edge $\left(x=1.01 c_{x}\right)$ and is normal to the tangential direction of the blade camber line at the trailing edge. At the design flow condition, the original linear turbulence closure predicts larger corner separation than the quadratic turbulence closure does, with the turbulence intensity core (maximum turbulence intensity) for both being centred around $9.4 \%$ chord and $7.54 \%$ chord from the blade suction surface, respectively. Similar trend can be seen in the case $i=2^{\circ}$, and the results are not shown here due to space limitations.

In order to more intuitively compare the mean vorticity field and Reynolds stress field below, a local coordinate system is setup with its three axes $s, y$, and $n$ respectively representing the streamwise, blade-spanwise, and
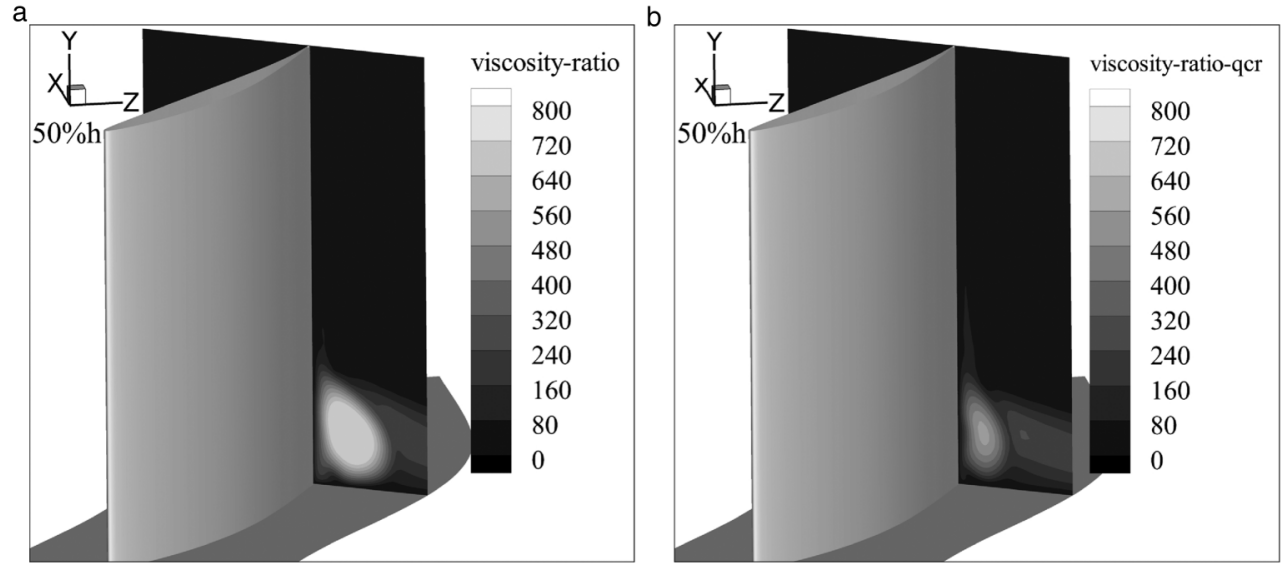

Figure 7. Comparison of the eddy-to-molecular viscosity ratio $\left(i=0^{\circ}\right)$. (a) BSL-2003-L, (b) BSL-2003-NL. 
blade-surface-normal directions (see in Figure 8). The velocity vector, vorticity vector and the Reynolds stress tensor that are computed in the Cartesian coordinate system are projected onto the new local coordinate system.

The generation of vortices in the corner can be described with the use of the streamwise ( $s$ axis) vorticity transport equation. With the assumption of incompressible and steady, this equation can be written as (Perkins, 1970):

$$
\begin{aligned}
\overline{u_{s}} \frac{\partial \varepsilon}{\partial s}+\overline{u_{n}} \frac{\partial \varepsilon}{\partial n}+\overline{u_{y}} \frac{\partial \varepsilon}{\partial y}= & v \nabla^{2} \varepsilon+\varepsilon \frac{\partial \bar{u}_{s}}{\partial s}+\eta \frac{\partial \overline{u_{s}}}{\partial n}+\zeta \frac{\partial \overline{u_{s}}}{\partial y}+\frac{\partial}{\partial s}\left(\frac{\partial\left\langle u_{s}^{\prime} u_{y}^{\prime}\right\rangle}{\partial n}-\frac{\partial\left\langle u_{s}^{\prime} u_{n}^{\prime}\right\rangle}{\partial y}\right) \\
& +\frac{\partial^{2}}{\partial n \partial y}\left(\left\langle u_{y}^{\prime} u_{y}^{\prime}\right\rangle-\left\langle u_{n}^{\prime} u_{n}^{\prime}\right\rangle\right)+\left(\frac{\partial^{2}}{\partial n^{2}}-\frac{\partial^{2}}{\partial y^{2}}\right)\left\langle u_{n}^{\prime} u_{y}^{\prime}\right\rangle
\end{aligned}
$$

where $(\varepsilon, \eta, \zeta)^{T}$ denotes the vorticity components in the local streamwise, wall-normal, and spanwise directions. $\left(\overline{u_{s}}, \overline{u_{n}}, \overline{u_{y}}\right)^{T}$ and $\left(u_{s}^{\prime}, u_{n}^{\prime}, u_{y}^{\prime}\right)^{T}$ denote the Reynolds-averaged velocities and Reynolds fluctuating components of velocity, respectively. In the right-hand side, let $P_{1}, P_{2}, P_{3}, P_{4}$ denote each part as:

$$
\begin{aligned}
& P_{1}=\varepsilon \frac{\partial \overline{u_{s}}}{\partial s}+\eta \frac{\partial \bar{u}_{s}}{\partial n}+\zeta \frac{\partial \bar{u}_{s}}{\partial y} \\
& P_{2}=\frac{\partial}{\partial s}\left(\frac{\partial\left\langle u_{s}^{\prime} u_{y}^{\prime}\right\rangle}{\partial n}-\frac{\partial\left\langle u_{s}^{\prime} u_{n}^{\prime}\right\rangle}{\partial y}\right) \\
& P_{3}=\frac{\partial^{2}}{\partial n \partial y}\left(\left\langle u_{y}^{\prime} u_{y}^{\prime}\right\rangle-\left\langle u_{n}^{\prime} u_{n}^{\prime}\right\rangle\right) \\
& P_{4}=\left(\frac{\partial^{2}}{\partial n^{2}}-\frac{\partial^{2}}{\partial y^{2}}\right)\left\langle u_{n}^{\prime} u_{y}^{\prime}\right\rangle
\end{aligned}
$$

According to Perkins, $P_{1}$ describes the production of streamwise vorticity through the deflexion, or shewing, of the mean shear by a transverse pressure gradient and/or body force, $P_{2}$ the production by primary shear stresses, $P_{3}$ the production by normal stress anisotropy, $P_{4}$ the production by secondary shear stress, and overall $P_{2}+P_{3}+P_{4}$ represents the production of streamwise vorticity by Reynolds stress gradients. For detailed expression of each source term on the new local coordinate system $s-y-n$, see the Appendix.

In the discussions below, the effect of the explicit anisotropic modification on the mean vorticity field is first illustrated by checking the streamwise vorticity source terms $P_{1}, P_{2}, P_{3}, P_{4}$, and the streamwise vorticity distribution upstream of the corner separation origin.

Figure 9 shows one selected cut plane that is normal to the blade camber line, i.e., $40 \% c_{x}$ (upstream of the corner separation origin). The contour plots of vorticity and vorticity source terms $P_{1}, P_{2}, P_{3}$, and $P_{4}$ are shown on this plane to illustrate the effect of the anisotropic modification on the generation of streamwise vortices in the corner region.

Figure 10 shows the distribution of $P_{1}$ change caused by the anisotropic modification of Reynolds stresses, i.e. $\left(\left(P_{1}\right)_{N E V}\right)$. The given anisotropic modification results in the generation of counter-rotating corner vortices around the corner. This is understandable as based on the RANS governing equations, the mean flow field is determined by the way the Reynolds stresses are modelled. This means that the change in $P_{1}$ is a resulting effect of the change

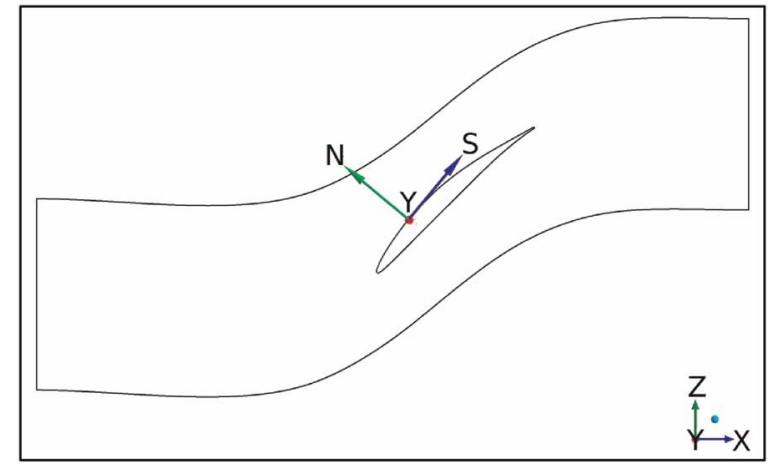

Figure 8. Notation for the $s-y-n$ local coordinate system. 


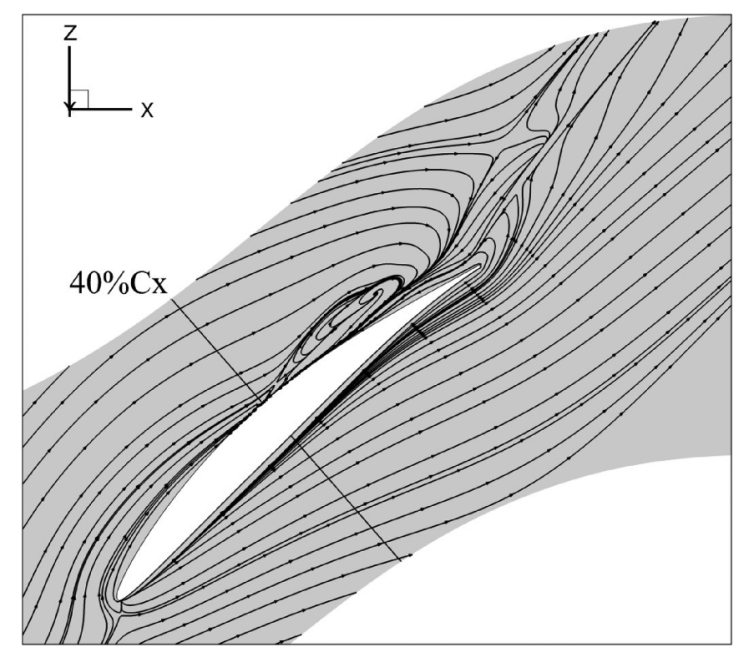

Figure 9. Endwall surface friction lines, BSL-2003-NL, $i=0^{\circ}$, with location of cut plane normal to the blade camber line.

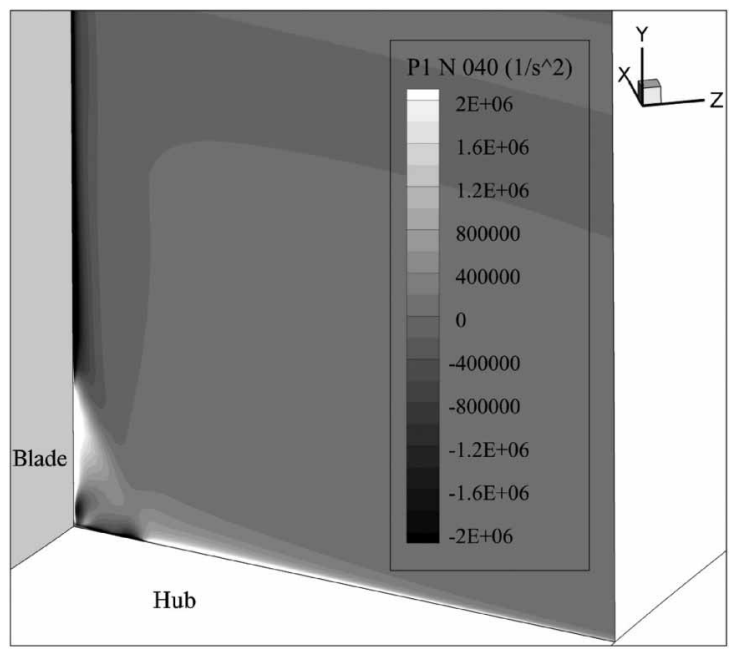

Figure 10. The net streamwise vorticity source term $\left(P_{1}\right)_{\text {NEV }}$ at $40 \% c_{X}\left(i=0^{\circ}\right)$.

in Reynolds stresses by the anisotropic modification given in this paper. Judging from the rotating direction of the corner vortices, higher-momentum fluid in the main passage flow is entrained into the corner area, making the corner flow more resistant to the adverse pressure gradient and thus delaying the onset of corner separation.

Figures 11, 12, and 13 show the distributions of the non-linear part of the source terms $\left(P_{2}\right)_{N E V},\left(P_{3}\right)_{N E V}$, $\left(P_{4}\right)_{N E V}$ on the cut plane $40 \% c_{x}$, respectively. The linear part $\left(P_{2}\right)_{E V},\left(P_{3}\right)_{E V},\left(P_{4}\right)_{E V}$ and the non-linear part $\left(P_{2}\right)_{N E V},\left(P_{3}\right)_{N E V},\left(P_{4}\right)_{N E V}$ are computed based on the solution from the BSL-2003-NL simulation. They are defined as the source terms $P_{2}, P_{3}$, and $P_{4}$ being solved by the linear and quadratic parts of the Reynolds stresses, respectively.

For example, the linear term $\left\langle u^{\prime} u^{\prime}\right\rangle_{E V}$ and the quadratic term $\left\langle u^{\prime} u^{\prime}\right\rangle_{N E V}$ of the axial normal stress $\left\langle u^{\prime} u^{\prime}\right\rangle$ are expressed as (see in equation (1) and (2)):

$$
\begin{gathered}
\left\langle u^{\prime} u^{\prime}\right\rangle_{E V}=\frac{2}{3} k-2 v_{t} S_{11} \\
\left\langle u^{\prime} u^{\prime}\right\rangle_{N E V}=\frac{1.2 v_{t}}{\max \left(0.3 \omega, \sqrt{0.5\left(S^{2}+\Omega^{2}\right)}\right)}\left(S_{1 k} \Omega_{k 1}-\Omega_{1 k} S_{k 1}\right) \\
\left\langle u^{\prime} u^{\prime}\right\rangle=\left\langle u^{\prime} u^{\prime}\right\rangle_{E V}+\left\langle u^{\prime} u^{\prime}\right\rangle_{N E V}
\end{gathered}
$$

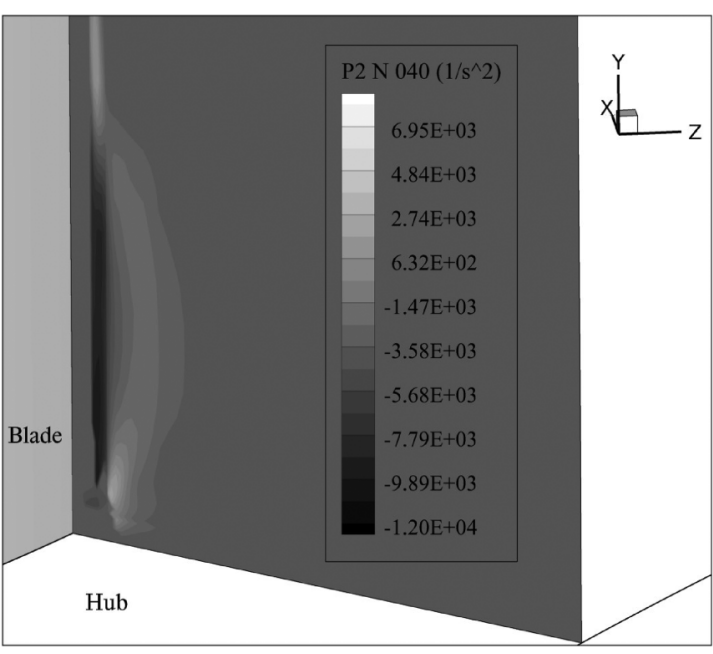

Figure 11. The non-linear part of the streamwise vorticity source term $\left(P_{2}\right)_{N E V}$ at $40 \% c_{x}\left(i=0^{\circ}\right)$.

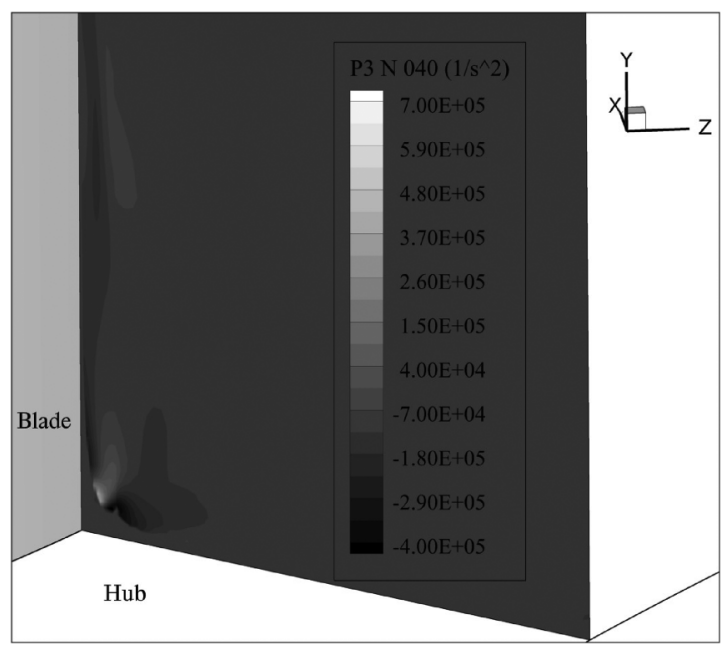

Figure 12. The non-linear part of the streamwise vorticity source term $\left(P_{3}\right)_{N E V}$ at $40 \% c_{x}\left(i=0^{\circ}\right)$. 


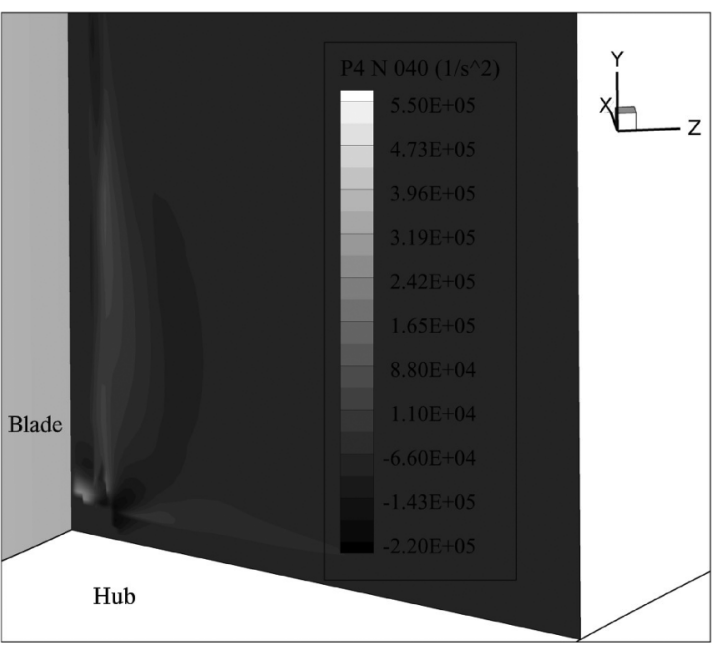

Figure 13. The non-linear part of the streamwise vorticity source term $\left(P_{4}\right)_{N E V}$ at $40 \% c_{X}\left(i=0^{\circ}\right)$.

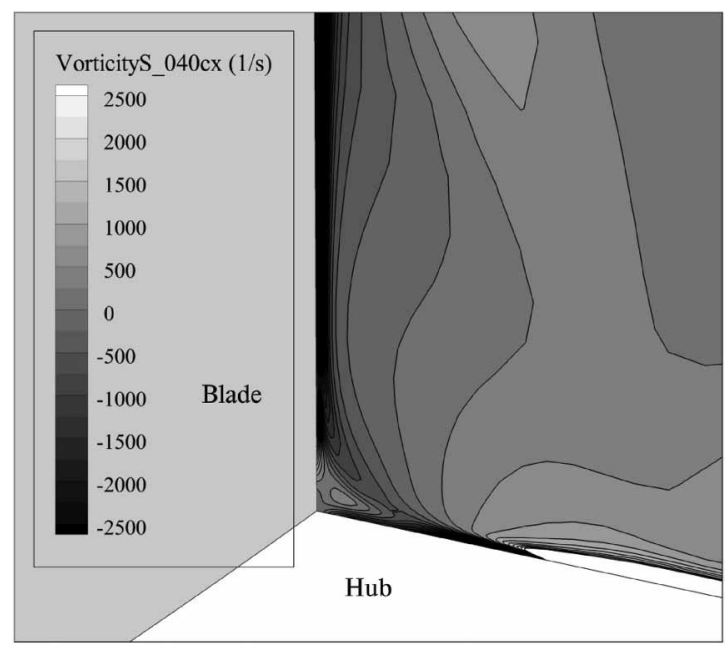

Figure 14. The streamwise vorticity at $40 \% c_{x}$, BSL-2003-L, $i=0^{\circ}$.

Similarly, each component of the Reynolds stress tensor can be split into its linear and quadratic parts. The footnotes 1, 2, 3 in the components of the strain/vorticity tensor denote axial, spanwise and pitchwise directions, respectively.

As seen from Figures 10,11, 12, and 13, in the corner region just upstream of the origin of separation (see in Figure 9), most of the streamwise vorticity production comes from $P_{1}, P_{3}$ and $P_{4}$, and those are of two orders of magnitude larger than that due to $P_{2}$. In Figures 10, 12 and 13, judging from the rotating direction of corner vortices, it can be concluded that the change in skewing of the mean shear, the anisotropic modification of the normal stress anisotropy $\left\langle u_{y}^{\prime} u_{y}^{\prime}\right\rangle-\left\langle u_{n}^{\prime} u_{n}^{\prime}\right\rangle$ and that of the secondary shear stress $\left\langle u_{n}^{\prime} u_{y}^{\prime}\right\rangle$ all contribute to the counter-rotating corner vortices produced in the corner region.

Figures 14 and 15 show the effect of the given anisotropic modification on the streamwise vorticity distribution on the cut plane at $40 \% c_{x}$. The incorporation of higher-order terms in the stress-strain relation results in the generation of counter-rotating corner vortices. This is consistent with the distribution of streamwise vorticity source terms $P_{1}, P_{3}$ and $P_{4}$ at $40 \% c_{x}$ (see in Figures 10, 12, and 13). Judging from the rotating direction of these two corner vortices, the higher-momentum fluid in the free space is entrained into the corner region, which energizes the corner flow and in turn delays the onset of separation.

The finding here shows consistency with that from the external flow community (Yamamoto et al., 2012; Mani et al., 2013; Dandois, 2014). In the numerical study of the turbulent square-duct flow (Mani et al.,

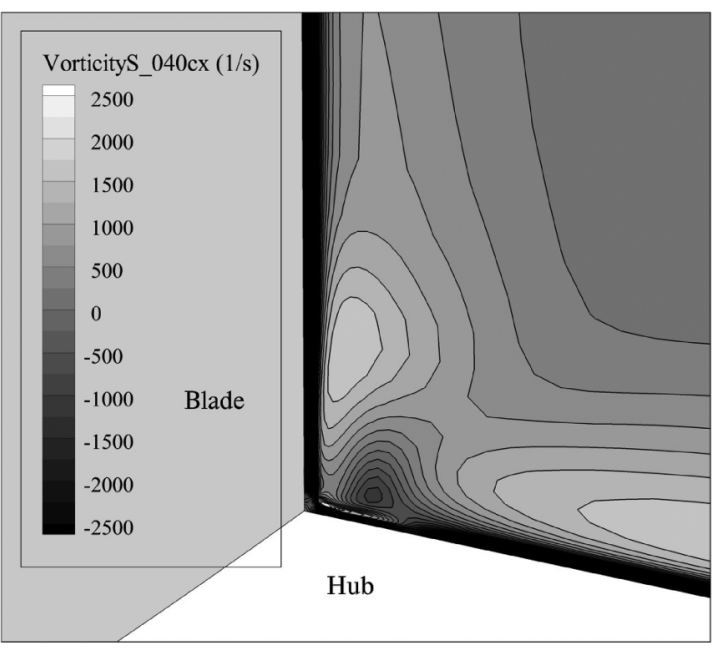

Figure 15. The streamwise vorticity at $40 \% c_{x}$, BSL-2003-NL, $i=0^{\circ}$.

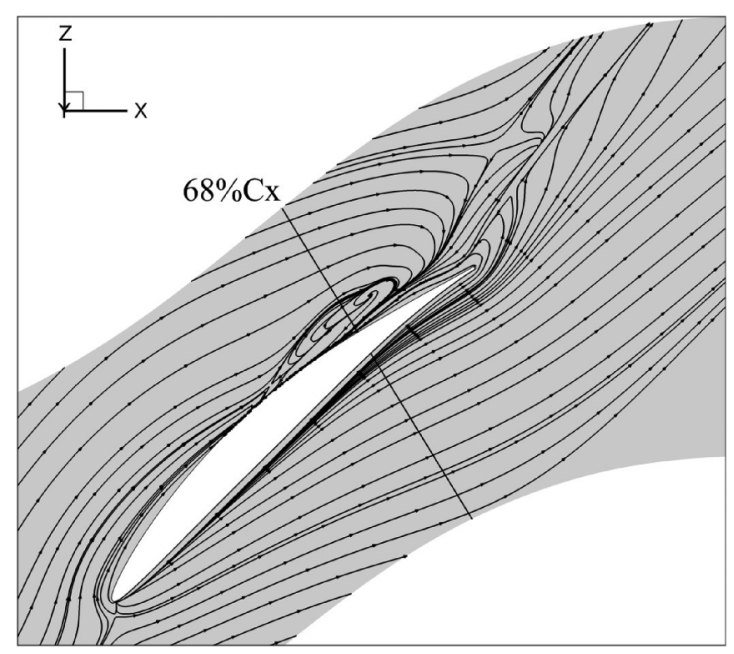

Figure 16. Endwall surface friction lines, BSL-2003-NL, $i=0^{\circ}$, with location of cut plane normal to the blade camber line. 


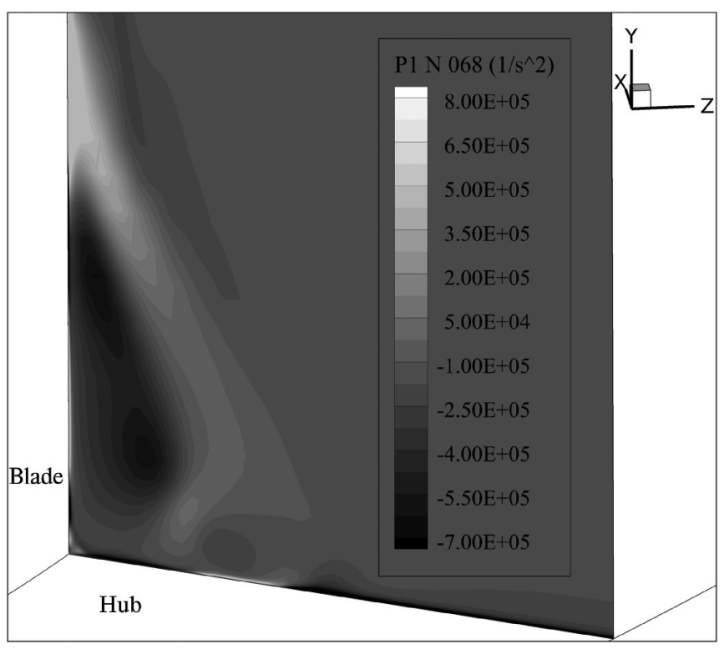

Figure 17. The net streamwise vorticity source term $\left(P_{1}\right)_{\text {NEV }}$ at $68 \% C_{X}\left(i=0^{\circ}\right)$.

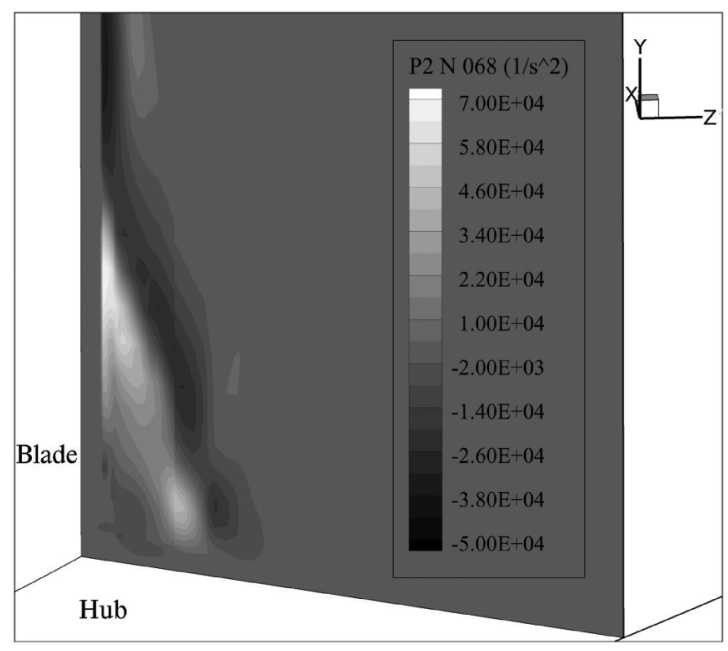

Figure 18. The non-linear part of the streamwise vorticity source term $\left(P_{2}\right)_{N E V}$ at $68 \% c_{X}\left(i=0^{\circ}\right)$.

2013), secondary corner vortices were observed around the corner of the duct by replacement of the Boussinesq closure by the quadratic constitutive relation (Spalart, 2000). The authors claimed that this is attributed to the capability of the quadratic constitutive relation to reproduce the physics of the normal stress anisotropy in the corner region, which leads to the appearance of corner vortices.

Next, the distributions of $P_{1}, P_{2}, P_{3}, P_{4}$ well within the corner separation are shown in relation to the flow behaviour within the corner separation region and in the separated shear layer between the mainstream flow and the corner separation flow.

Figure 16 shows the selected cut plane, and again it is normal to the blade camber line, i.e. $68 \% c_{x}$. The contour plots of streamwise vorticity and vorticity source terms are shown on this plane to illustrate the effect of the anisotropic modification on the generation of streamwise vortices within the corner separation region.

Within the corner separation region $\left(68 \% c_{x}\right)$, as shown from Figures 17, 18, 19, and 20, most of the streamwise vorticity production comes from $P_{1}, P_{3}$ and $P_{4}$. The contribution of the anisotropic modification of the primary shear stresses $\left\langle u_{s}^{\prime} u_{y}^{\prime}\right\rangle,\left\langle u_{s}^{\prime} u_{n}^{\prime}\right\rangle$ in $P_{2}$ to the streamwise vorticity production (shown in Figure 18) is significantly larger than that upstream of the corner separation region $\left(40 \% c_{x}\right)$ (see in Figure 11). However, it is still significantly smaller compared to the change of other three terms.

As seen in Figure 17, the contribution of the mean shear skewing to the streamwise vorticity generation mainly concentrates in the separated shear layer between the corner separation region and the main flow where

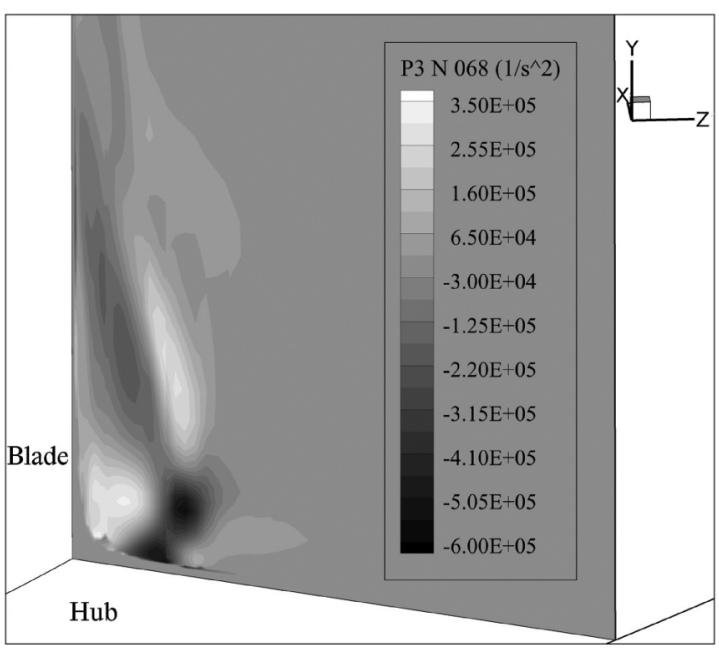

Figure 19. The non-linear part of the streamwise vorticity source term $\left(P_{3}\right)_{N E V}$ at $68 \% c_{x}\left(i=0^{\circ}\right)$.

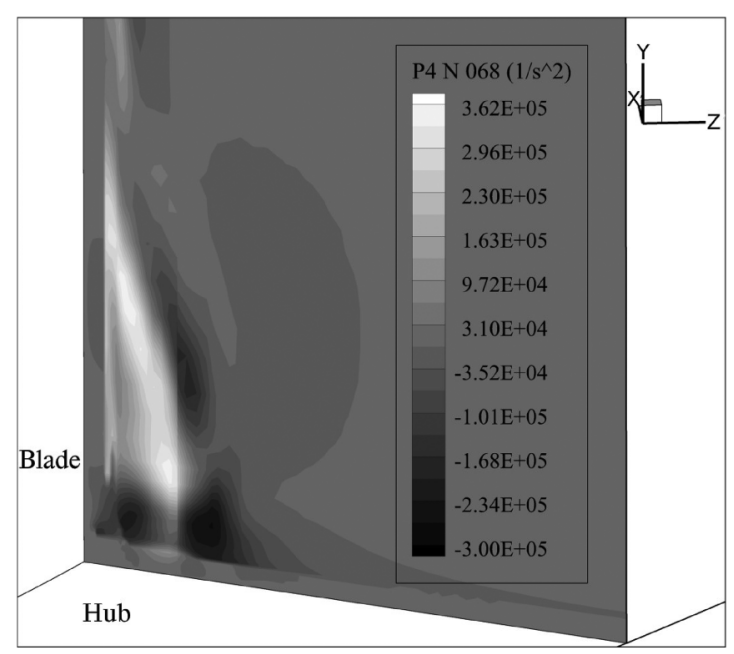

Figure 20. The non-linear part of the streamwise vorticity source term $\left(P_{4}\right)_{N E V}$ at $68 \% c_{X}\left(i=0^{\circ}\right)$. 
counter-rotating vortices coexist, which enhances the turbulent shear between the corner separation flow and the main passage flow. This contributes to the stronger momentum exchange between the flow outside the separation region and the corner separation flow, energizing the flow inside the corner separation and making it resistant to bulk adverse pressure gradients.

Similar trend can be seen in Figures 19 and 20. The anisotropic modification of the normal stress anisotropy in $P_{3}$ and the secondary shear stress in $P_{4}$ leads to more and stronger streamwise vortices generated both along the outer layer of corner separation and within the separation region. This indicates that strong shear shall exist both between the main flow and the corner separation flow and within the separation region. Again, this leads to stronger momentum exchange between the main passage flow and the corner separation, which energies the corner flow and makes it more resistant to separation.

In summary, it can be clearly seen that the inclusion of the Reynolds stress anisotropy contributes to the induction of the streamwise vorticities in the corner region. Next, the streamwise vorticity distributions are shown in Figures 21 and 22 to illustrate the effect of the Reynolds stress change on the streamwise vorticity field.

Within the corner separation region, the streamwise vorticity contour lines of BSL-2003-NL concentrate in the separated shear layer between the corner region and the main flow region that are close to the endwall (see in Figure 22). This is consistent with the distribution of the streamwise vorticity source terms $P_{3}$ and $P_{4}$ at $68 \% c_{x}$ (see in Figures 19 and 20). This indicates that stronger shear interaction occurs in the separated shear layer between the main flow and the corner separation flow, thus resulting in the higher-momentum fluid in the free space being entrained into the corner region. The corner flow is energized and in turn is more resistant to separation.

\section{Conclusions}

In the present research, a recently proposed quadratic stress-strain constitutive relation based on the $k-\omega$ type turbulence models has been used to numerically investigate the corner separation flows in the compressor blade passage. The following conclusions can be drawn from this study:

- In comparison with the original Boussinesq constitutive relation does, the non-linear, quadratic constitutive relation, when coupled with the Menter's hybrid $k-\omega / k-\varepsilon$ model, does give considerably better predictions for the extent of corner separation, at both design and off-design inflow conditions.

- One of the physical reasons for the improved predictive capabilities is that the inclusion of the quadratic strain-vorticity term to the Boussinesq Reynolds-stress closure increases the Reynolds stress anisotropy, which
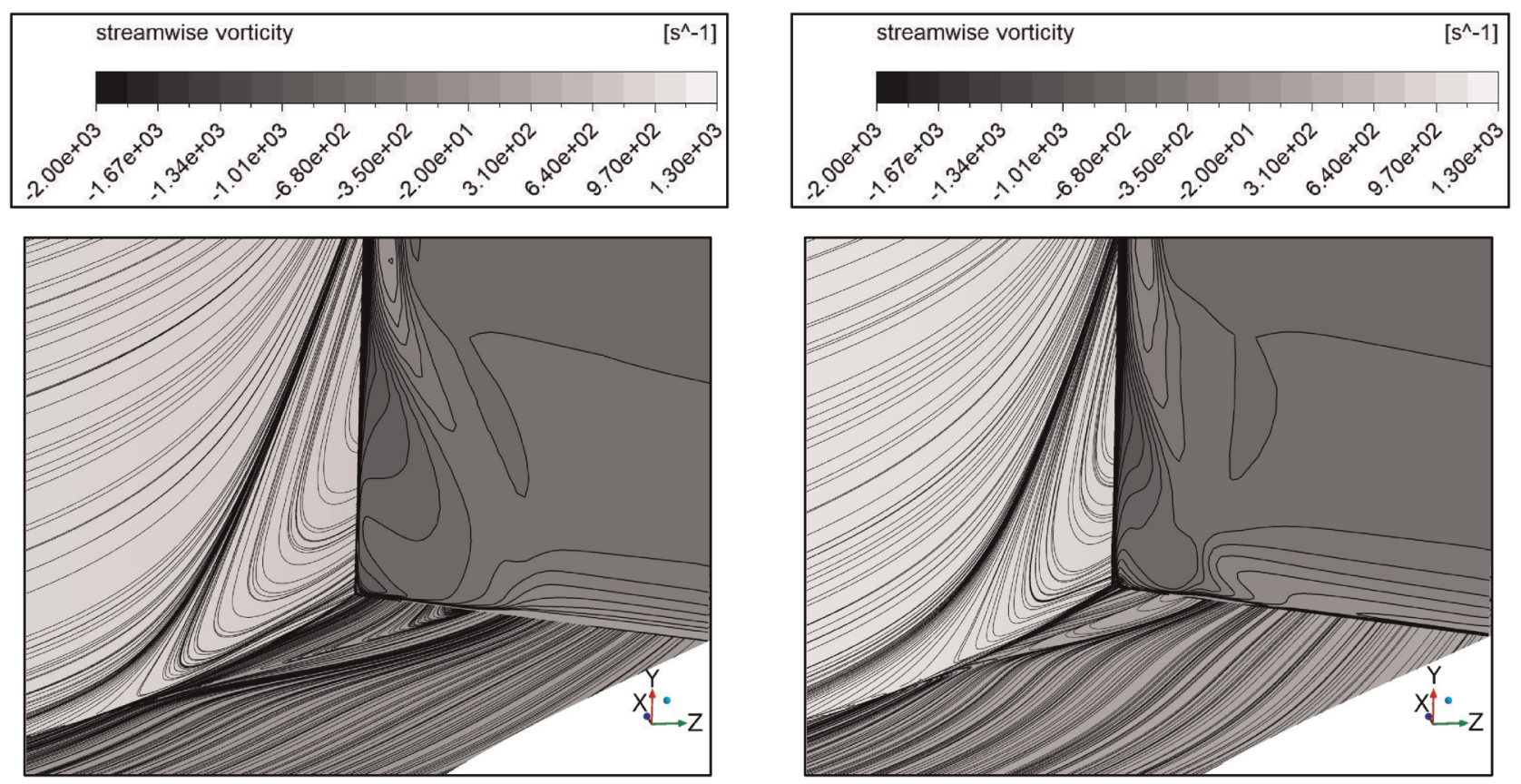

Figure 21. The streamwise vorticity at $68 \% c_{x}$, BSL-2003-L, surface friction lines, $i=0^{\circ}$.

Figure 22. The streamwise vorticity at $68 \% c_{x}$, BSL-2003-NL, surface friction lines, $i=0^{\circ}$. 
contributes to the counter-rotating streamwise vortices being generated in the corner region, and the stronger turbulent shear interaction in the separated shear layer. This in turn leads to more of the higher-momentum fluid in the main passage flow being entrained into the corner region, in which the flow is energized and thus is more resistant to separation.

- The engineering analysis of the corner separation flow mainly focuses on the prediction of the blockage due to separation. Considering this, the Menter et al.'s nonlinear explicit RANS turbulence closure shows its strong potential in determining the corner separation size with reasonable accuracy, while maintaining the low cost, numerical robustness, and convenience for implementation.

- However, as the inlet flow incidence is increased, the corner separation becomes larger and more complex. More significant discrepancies between the CFD results and the experimental measurements are observed in terms of the blockage. Herein it shall be realized that the effect of the turbulence anisotropy on corner flow structures is characterized by modelling. The modelling uncertainties still exist at off-design flow conditions. This calls for the high-fidelity scale-resolving simulations in order to obtain understandings of the source of the anisotropy based on turbulence resolved simulation results. Further improvement of the Menter et al.'s nonlinear turbulence closure could be carried out based on the insight and understandings gained from further studies of the scale-resolving flow solutions.

\section{Nomenclature}

$C_{p s} \quad$ static pressure coefficient, $\left(p-p_{1}\right) /\left(p_{01}-p_{1}\right)$

$i \quad$ inlet incidence angle, degree

$k$ turbulence kinetic energy, $\mathrm{m}^{2} / \mathrm{s}^{2}$

$p \quad$ local static pressure, $\mathrm{Pa}$

$p_{1} \quad$ endwall static pressure at inlet, $\mathrm{Pa}$

$p_{01}$ freestream total pressure at inlet, $\mathrm{Pa}$

$T u$ freestream turbulence intensity, $\sqrt{\overline{\left(u^{\prime}\right)^{2}}} / U_{\infty}$

$u_{\tau}$ wall-friction velocity, $\mathrm{m} / \mathrm{s}$

$u^{+}$non-dimensional mean velocity, $u / u_{\tau}$

$u^{\prime}$ fluctuating velocity in the axial direction, $\mathrm{m} / \mathrm{s}$

$U_{\infty}$ freestream velocity at inlet, $\mathrm{m} / \mathrm{s}$

$v \quad$ kinematic viscosity of the working fluid, $\mathrm{m}^{2} / \mathrm{s}$

$v^{\prime} \quad$ fluctuating velocity in the spanwise direction, $\mathrm{m} / \mathrm{s}$

$w^{\prime} \quad$ fluctuating velocity in the pitchwise direction, $\mathrm{m} / \mathrm{s}$

$y \quad$ wall-normal distance, $\mathrm{m}$

$y^{+}$non-dimensional wall-normal distance, $u_{\tau} y / v$

$\theta$ rotating angle between the local coordinate system $s-y$ - $n$ and the Cartesian coordinate system $x-y-z$

$\langle\varphi\rangle$ Reynolds average of $\varphi$

$\omega$ specific dissipation rate, $1 /$ s

\section{Subscripts}

ps static pressure

1 cascade inlet

$\infty \quad$ inlet freestream

$E V$ linear part in the quadratic stress-strain constitutive relation

$N E V$ non-linear part in the quadratic stress-strain constitutive relation

\section{Appendix}

The source terms in the streamwise vorticity transport equations are expressed on the new local $s-y$ - $n$ coordinate system (see in equations (9)-(12) and Figure 8). These are obtained based on the Chain rule and the Galilean 
invariance, with detailed expressions listed below:

$$
\begin{aligned}
& P_{1}=\omega_{z} \frac{\partial \overline{u_{z}}}{\partial z} \cos ^{3} \theta+\omega_{y} \frac{\partial \overline{u_{z}}}{\partial z} \sin \theta \cos ^{2} \theta+\omega_{z} \frac{\partial \overline{u_{y}}}{\partial z} \sin \theta \cos ^{2} \theta+\omega_{y} \frac{\partial \overline{u_{y}}}{\partial z} \sin ^{2} \theta \cos \theta+\omega_{z} \frac{\partial \overline{u_{z}}}{\partial y} \sin \theta \cos ^{2} \theta \\
& +\omega_{y} \frac{\partial \overline{u_{z}}}{\partial y} \sin ^{2} \theta \cos \theta+\omega_{z} \frac{\partial \overline{u_{y}}}{\partial y} \sin ^{2} \theta \cos \theta+\omega_{y} \frac{\partial \overline{u_{y}}}{\partial y} \sin ^{3} \theta+\omega_{y} \frac{\partial \overline{u_{z}}}{\partial y} \cos ^{3} \theta-\omega_{z} \frac{\partial \overline{u_{z}}}{\partial y} \sin \theta \cos ^{2} \theta \\
& +\omega_{y} \frac{\partial \overline{u_{y}}}{\partial y} \sin \theta \cos ^{2} \theta-\omega_{z} \frac{\partial \overline{u_{y}}}{\partial y} \sin ^{2} \theta \cos \theta-\omega_{y} \frac{\partial \overline{u_{z}}}{\partial z} \sin \theta \cos ^{2} \theta+\omega_{z} \frac{\partial \overline{u_{z}}}{\partial z} \sin ^{2} \theta \cos \theta \\
& -\omega_{y} \frac{\partial \overline{u_{y}}}{\partial z} \sin ^{2} \theta \cos \theta+\omega_{z} \frac{\partial \overline{u_{y}}}{\partial z} \sin ^{3} \theta+\omega_{x} \frac{\partial \overline{u_{z}}}{\partial x} \cos \theta+\omega_{x} \frac{\partial \overline{u_{y}}}{\partial x} \sin \theta \\
& P_{2}=\sin ^{2} \theta \cos \theta \frac{\partial^{2}\left\langle u^{\prime} v^{\prime}\right\rangle}{\partial y^{2}}+\sin \theta \cos ^{2} \theta \frac{\partial^{2}\left\langle u^{\prime} w^{\prime}\right\rangle}{\partial y^{2}}-\sin ^{3} \theta \frac{\partial^{2}\left\langle u^{\prime} v^{\prime}\right\rangle}{\partial y \partial z}-\sin ^{2} \theta \cos \theta \frac{\partial^{2}\left\langle u^{\prime} w^{\prime}\right\rangle}{\partial y \partial z} \\
& +\sin \theta \cos ^{2} \theta \frac{\partial^{2}\left\langle u^{\prime} v^{\prime}\right\rangle}{\partial y \partial z}+\cos ^{3} \theta \frac{\partial^{2}\left\langle u^{\prime} w^{\prime}\right\rangle}{\partial y \partial z}-\sin ^{2} \theta \cos \theta \frac{\partial^{2}\left\langle u^{\prime} v^{\prime}\right\rangle}{\partial z^{2}}-\sin \theta \cos ^{2} \theta \frac{\partial^{2}\left\langle u^{\prime} w^{\prime}\right\rangle}{\partial z^{2}} \\
& -\sin ^{2} \theta \cos \theta \frac{\partial^{2}\left\langle v^{\prime} v^{\prime}\right\rangle}{\partial x \partial y}+\sin ^{3} \theta \frac{\partial^{2}\left\langle v^{\prime} w^{\prime}\right\rangle}{\partial x \partial y}-\sin \theta \cos ^{2} \theta \frac{\partial^{2}\left\langle v^{\prime} w^{\prime}\right\rangle}{\partial x \partial y}+\sin ^{2} \theta \cos \theta \frac{\partial^{2}\left\langle w^{\prime} w^{\prime}\right\rangle}{\partial x \partial y} \\
& -\sin \theta \cos ^{2} \theta \frac{\partial^{2}\left\langle v^{\prime} v^{\prime}\right\rangle}{\partial x \partial z}+\sin ^{2} \theta \cos \theta \frac{\partial^{2}\left\langle v^{\prime} w^{\prime}\right\rangle}{\partial x \partial z}-\cos ^{3} \theta \frac{\partial^{2}\left\langle v^{\prime} w^{\prime}\right\rangle}{\partial x \partial z}+\sin \theta \cos ^{2} \theta \frac{\partial^{2}\left\langle w^{\prime} w^{\prime}\right\rangle}{\partial x \partial z} \\
& P_{3}=\cos \theta \frac{\partial^{2}\left\langle u^{\prime} u^{\prime}\right\rangle}{\partial x \partial y}-\cos ^{3} \theta \frac{\partial^{2}\left\langle v^{\prime} v^{\prime}\right\rangle}{\partial x \partial y}+2 \sin \theta \cos ^{2} \theta \frac{\partial^{2}\left\langle v^{\prime} w^{\prime}\right\rangle}{\partial x \partial y}-\sin ^{2} \theta \cos \theta \frac{\partial^{2}\left\langle w^{\prime} w^{\prime}\right\rangle}{\partial x \partial y}-\sin \theta \frac{\partial^{2}\left\langle u^{\prime} u^{\prime}\right\rangle}{\partial x \partial z} \\
& +\sin \theta \cos ^{2} \theta \frac{\partial^{2}\left\langle v^{\prime} v^{\prime}\right\rangle}{\partial x \partial z}-2 \sin ^{2} \theta \cos \theta \frac{\partial^{2}\left\langle v^{\prime} w^{\prime}\right\rangle}{\partial x \partial z}+\sin ^{3} \theta \frac{\partial^{2}\left\langle w^{\prime} w^{\prime}\right\rangle}{\partial x \partial z} \\
& P_{4}=\cos ^{3} \theta \frac{\partial^{2}\left\langle u^{\prime} v^{\prime}\right\rangle}{\partial y^{2}}-2 \sin \theta \cos ^{2} \theta \frac{\partial^{2}\left\langle u^{\prime} v^{\prime}\right\rangle}{\partial y \partial z}+\sin ^{2} \theta \cos \theta \frac{\partial^{2}\left\langle u^{\prime} v^{\prime}\right\rangle}{\partial z^{2}}-\sin \theta \cos ^{2} \theta \frac{\partial^{2}\left\langle u^{\prime} w^{\prime}\right\rangle}{\partial y^{2}} \\
& +2 \sin ^{2} \theta \cos \theta \frac{\partial^{2}\left\langle u^{\prime} w^{\prime}\right\rangle}{\partial y \partial z}-\sin ^{3} \theta \frac{\partial^{2}\left\langle u^{\prime} w^{\prime}\right\rangle}{\partial z^{2}}-\cos \theta \frac{\partial^{2}\left\langle u^{\prime} v^{\prime}\right\rangle}{\partial x^{2}}+\sin \theta \frac{\partial^{2}\left\langle u^{\prime} w^{\prime}\right\rangle}{\partial x^{2}}
\end{aligned}
$$

where $\left(\omega_{x}, \omega_{y}, \omega_{z}\right)^{T}$ denotes the vorticity vector in Cartesian coordinates; $\theta$ is the angle between the $x-y-z$ coordinate system and the $s-y-n$ coordinate system in the anti-clockwise rotation direction.

\section{Acknowledgments}

The authors would like to thank Prof. Xavier Ottavy of École Centrale de Lyon for providing the cascade geometry and part of the experimental data of the LMFA-NACA65 compressor cascade. The authors would also like to thank Dr. Yu Xia of ANSYS UK Ltd for his technical service supports on the implementation of user-defined macros in FLUENT. Comments, questions and suggestions from anonymous reviewers are deeply appreciated.

\section{Funding sources}

The corresponding author Wei Sun's own funding for the work submitted.

\section{Competing interests}

Wei Sun declares that he has no conflict of interest. Liping Xu declares that he has no conflict of interest.

\section{References}

Boussinesq J. (1903). Théorie analytique de la chaleur mise en harmonic avec la thermodynamique et avec la théorie mécanique de la lumière: Tome I-[II], Vol. 2: Gauthier-Villars, Paris. 
Dandois J. (2014). Improvement of corner flow prediction using the quadratic constitutive relation. AIAA Journal. 52 (12): $2795-2806$. https://doi.org/10.2514/1.J052976

Dong Y., Gallimore S. J., and Hodson H. P. (1986). Three-dimensional flows and loss reduction in axial compressors. In: ASME 1986 International Gas Turbine Conference and Exhibit. American Society of Mechanical Engineers Digital Collection.

Gatski T. B., and Speziale C. G. (1993). On explicit algebraic stress models for complex turbulent flows. Journal of Fluid Mechanics. 254: 59-78. https://doi.org/10.1017/S0022112093002034

Gbadebo S. A., Cumpsty N. A., and Hynes T. P. (2005). Three-dimensional separations in axial compressors. Journal of Turbomachinery. 127 (2): 331-339. https://doi.org/10.1115/1.1811093

Hanjalić K. and Launder B. E. (1976). Contribution towards a reynolds-stress closure for low-reynolds-number turbulence. Journal of Fluid Mechanics. 74 (4): 593-610. https://doi.org/10.1017/S0022112076001961

Hellsten A. and Wallin S. (2009). Explicit algebraic reynolds stress and non-linear eddy-viscosity models. International Journal of Computational Fluid Dynamics. 23 (4): 349-361. https://doi.org/10.1080/10618560902776828

Liu Y., Yan H., Liu Y., Lu L., and Li Q. (2016). Numerical study of corner separation in a linear compressor cascade using various turbulence models. Chinese Journal of Aeronautics. 29 (3): 639-652. https://doi.org/10.1016/j.cja.2016.04.013

Lu L., Zhong L., and Liu Y. (2016). Turbulence models assessment for separated flows in a rectangular asymmetric three-dimensional diffuser. Engineering Computations. 33 (4): 978-994. https://doi.org/10.1108/EC-05-2015-0112

Ma W., Ottavy X., Lu L., Leboeuf F., and Gao F. (2011). Experimental investigations of corner stall in a linear compressor cascade. Proceedings of the ASME 2011 Turbo Expo: Turbine Technical Conference and Exposition, 7, pp. 39-51.

Mani M., Babcock D., Winkler C., and Spalart P. (2013). Predictions of a supersonic turbulent flow in a square duct. In: $51 s t$ AIAA Aerospace Sciences Meeting Including the New Horizons Forum and Aerospace Exposition, p. 860.

Menter F. R. (1994). Two-equation eddy-viscosity turbulence models for engineering applications. AIAA Journal. 32 (8): 1598-1605. https://doi.org/10.2514/3.12149

Menter F. R., Kuntz M., and Langtry R. (2003). Ten years of industrial experience with the SST turbulence model. Turbulence, Heat and Mass Transfer. 4 (1): 625-632.

Menter F. R., Matyushenko A., and Lechner R. (2018). Development of a generalized k- $\omega$ two-equation turbulence model. In: Symposium der Deutsche Gesellschaft für Luft-und Raumfahrt, pp. 101-109.

Mishra A. A. and Iaccarino G. (2017). RANS predictions for high-speed flows using enveloping models. arXiv preprint arXiv: 1704. 01699.

Perkins H. J. (1970). The formation of streamwise vorticity in turbulent flow. Journal of Fluid Mechanics. 44 (4): 721-740. https://doi. org/10.1017/S0022112070002112

Pope S. B. (1975). A more general effective-viscosity hypothesis. Journal of Fluid Mechanics. 72 (2): 331-340. https://doi.org/10.1017/ S0022112075003382

Spalart P. R. and Allmaras S. (1992). A one-equation turbulence model for aerodynamic flows. In: 30th Aerospace Sciences Meeting and Exhibit, p. 439.

Spalart P. R. (2000). Strategies for turbulence modelling and simulations. International Journal of Heat and Fluid Flow. 21 (3): $252-263$. https://doi.org/10.1016/S0142-727X(00)00007-2

Spalart P. R. (2015). Philosophies and fallacies in turbulence modeling. Progress in Aerospace Sciences. 74: 1-15. https://doi.org/10.1016/j. paerosci.2014.12.004

Su X. and Yuan X. (2017). Improved compressor corner separation prediction using the quadratic constitutive relation. Proceedings of the Institution of Mechanical Engineers, Part A: Journal of Power and Energy. 231 (7): 618-630.

Wilcox D. C. (1988). Reassessment of the scale-determining equation for advanced turbulence models. AIAA Journal. 26 (11): 1299-1310. https://doi.org/10.2514/3.10041

Yamamoto K., Tanaka K., and Murayama M. (2012). Effect of a nonlinear constitutive relation for turbulence modeling on predicting flow separation at wing-body juncture of transonic commercial aircraft. In: 30th AIAA Applied Aerodynamics Conference, p. 2895.

Zambonini G., Ottavy X., and Kriegseis J. (2016). Corner separation dynamics in a linear compressor cascade. In: ASME Turbo Expo 2016: Turbomachinery Technical Conference and Exposition. American Society of Mechanical Engineers Digital Collection. 